\section{Re: Antibiotikabruk i sykehus og sykehjem}

I Tidsskriftet nr. 5/2017 omtales økende antibiotikaresistens (1) og bruk av bredspektret antibiotika ved urinveisinfeksjoner på sykehjem (2) med budskap om å følge de nasjonale retningslinjene for antibiotika bruk i primærhelsetjenesten (3). Vi har nylig publisert en evaluering av urindyrkningssvar og empirisk behandling hos 161 ikke-gravide kvinner med mistenkt akutt cystitt i en solopraksis (4). Vi fant signifikant oppvekst hos $62 \%$ av 126 pasienter som startet antibiotikabehandling. E.coli stod for $75 \%$ av infeksjonene, og for alle påviste bakterier var hyppigheten av resistens mot nitrofurantoin $7 \%$, pivmecillinam $20 \%$, trimethoprim $20 \%$ og amoxicillin $33 \%$. For de to mest brukte antibiotika - pivmecillinam og trimethoprim - må man altså kunne påregne terapisvikt hos opptil $20 \%$ av pasientene. 15 pasienter $(9 \%)$ hadde glede av dyrkningssvaret ved at de enten skiftet $(n=10)$ eller startet $(n=5)$ antibiotikabehandling.

Tilsvarende fant vi positiv nasofarynksdyrkningssvar hos knapt halvparten av pasientene med akutt sinusitt $(n=220)$ (upubliserte datea). Etter retningslinjene skal penicillin være førstevalg og behandling først gis etter symptomvarighet på minst en uke (3). I vår studie var bare $43 \%$ av bakteriene følsomme for penicillin, hovedsakelig pga. oppvekst av Haemophilus influenzae (42\%) og Moraxella catarrhalis (10\%). Det bemerkes også at det ikke var noen signifikant forskjell i varighet av symptomer mellom de med og uten oppvekst. $14 \%$ av pasientene enten skiftet $(n=18)$ eller startet antibiotikabehandling $(\mathrm{n}=13)$ ut fra oppvekstsvar og manglende klinisk bedring. Vi antar at mange allmennpraktikere har tilsvarende erfaring med terapisvikt med penicillin ved bihulebetennelse, og at noen pasienter ikke lar seg motivere til å avvente behandling den første uken med symptomer.

Vi støtter opp under de norske retningslinjene for antibiotikabehandling ved cystitt og sinusitt, men vårt budskap er for det første at mange cystitter og sinusitter kan gå spontant over uten antibiotikabehandling. For det andre kan på fastlegekontorer dyrkningsprøver motivere pasienter til å avvente behandling og sikre målrettet antibiotikabehandling ved manglende spontanbedring. Man må dessverre akseptere at en del vil trenge bredspektret antibiotika. Denne fremgangsmåten vil føre til økt mikrobiologisk prøvetakning, men kan bidra til redusert bruk av antibiotika og mer målrettet behandling. For det tredje kan i legevaktsammenheng en vent-ogse-resept være en løsning, men norske erfaringer viser at knapt halvparten av pasientene henter ut en slik resept (5).

\section{Stephanie Knudtzon \\ stephanie.knudtzon@gmail.com \\ Jørgen Knudtzon}

Stephanie Knudtzon (f. 1992) er medisinstudent ved Norges teknisknaturvitenskapelige universitet i Trondheim.

Ingen oppgitte interessekonflikter.

Jørgen Knudtzon (f. 1954) er spesialist i barnesykdommer og allmennmedisin, og fastlege ved Sinsen legesenter.

Ingen oppgitte interessekonflikter.

\section{Litteratur}

1. Simonsen GS. Antibiotikabruk i sykehus og sykehjem. Tidsskr Nor Legeforen 2017; 137: 340

2. Alberg T, Holen $\emptyset$. Blix HS et al. Antibiotikabruk og infeksjoner i sykehjem. Tidsskr Nor Legeforen 2017; 137: 357-61.

3. Antibiotikabruk i primærhelsetjenesten. www.antibiotikaiallmennpraksis.no/ (11.3.2017).

4. Knudtzon S, Knudtzon J. Usefulness of urine culture from healthy non-pregnant women with uncomplicated cystitis. Infect Dis (Lond) 2017; Mar 3: 1-3.

5. Høye S, Frich J, Lindbœk M. Delayed prescribing for upper respiratory tract infections: a qualitative study of GPs' views and experiences. Br J Gen Pract 2010; 60: $907-12$.

\section{Re: Etikk og estetikk ved prehospital torakotomi}

Vi setter pris på det store engasjementet som vårt innlegg om prehospital torakotomi i Tidsskriftet nr. 23-24/2016 har skapt (1). Søreide og medarbeidere er i sitt innlegg (2) kritiske til ressursbruken knyttet til etableringen av denne prosedyren i Norge og argumenterer for at inngrepet kan være skadelig. Det er meget viktig å understreke at prehospital torakotomi kun skal vurderes utført på selekterte pasienter med traumatisk hjertestans grunnet penetrerende skade som man ellers ville erklært døde på skadestedet (3-5). Med dette som bakgrunn er det derfor vanskelig å se at inngrepet kan være skadelig. Videre mener vi mener at lav forekomst av en tilstand ikke alene utgjør et gyldig argument for ikke å anvende en potensielt livreddende prosedyre. Eksempelvis unnlater vi ikke å etablere kirurgisk luftvei i en kritisk situasjon på en pasient med det argument at prosedyren utføres sjeldent. Sammenlikningen mellom prehospital torakotomi og kirurgisk luftvei er relevant. Det er ytterst sjeldent behov for å utføre disse prosedyrene, og kunnskapen om dem baserer seg på kasusserier $(6,7)$.

Det henvises til argumentet om uforsvarlig ressursbruk. Trening på torakotomi foregår imidlertid i allerede etablerte kurs der blødningskontroll, avlasting av overtrykkspneumothoraks og vanskelig luftvei har hovedfokus. Den resucitative torakotomiprosedyren innøves i forlengelsen av trening på avlasting av overtrykkspneumothoraks, og legger i liten grad beslag på ytterligere ressurser. Det er derfor ikke korrekt når det hevdes at trening på prehospital torakotomi er uansvarlig bruk av helseressurser.

Søreide og medarbeidere refererer til en artikkel som viser at uavlastet overtrykkspneumothorax er en av hovedårsakene til dødsfall ved traumatisk hjertestans og at prehospital torakotomi ikke er indisert for å avlaste denne (8). Vi beklager at det i beskrivelsen av prosedyren i vår artikkel ved en inkurie ble oppgitt at det initialt utføres bilateral torakotomi - det korrekte er at det utføres bilateral torakostomi. Hvis pasienten på dette tidspunktet gjenvinner sirkulasjon på grunn av avlastet overtrykkspneumothorax, avbrytes prosedyren. Søreide og medarbeidere opplyser videre at tre av fire behandlingsfeil ved traumatisk hjertestans forekommer prehospitalt (8). Vi har utelukkende drøftet prehospital thorakotomi ved penetrerende skademekanisme, men i den artikkelen det refereres til, omtaler man imidlertid en studie av traumatisk hjertestans hos barn ved stump skademekanisme, og dette er ikke sammenlignbare pasientgrupper (9). Videre skriver de avslutningsvis: «Eksperimentelle metoder bør uansett ikke innføres uten at de implementeres i en etisk godkjent studie». Hva som kan betraktes som «eksperimentelt» er ikke entydig, og mange tiltak i akuttmedisinen baserer seg på sparsomt kunnskapsgrunnlag. Enten vi befinner oss ved operasjonsbordet, på intensivavdelingen eller på fortauet, må vi fortsatt kunne bruke anatomisk og fysiologisk forståelse i møte med våre aller sykeste pasienter.

\section{William Ottestad \\ Per B. Bredmose \\ Per Olav Berve \\ Halvard Stave \\ Gunnar Farstad \\ Lars Wik \\ Mårten Sandberg}

marten.sandberg@gmail.com

William Ottestad (f. 1974) er spesialist i anestesiologi og overlege ved Luftambulanseavdelingen, Oslo universitetssykehus.

Ingen oppgitte interessekonflikter.

Per B. Bredmose (f. 1973) er spesialist i anestesiologi og jobber som overlege med prehospital medisin og transportmedisin ved Luftambulanseavdelingen, Oslo universitetssykehus. Forfatteren har tidligere jobbet ved London's Air Ambulance fra The Royal London Hospital i London og har erfaring med prehospital torakotomi og medisinsk pedagogikk og undervisning i denne prosedyren.

Ingen oppgitte interessekonflikter. 